\title{
Poéticas del bolso. Las poetas cubanas: reflexiones metapoéticas en Carilda Oliver, Fina García Marruz, Reina María Rodríguez y Damaris Calderón
}

En su ensayo «El poema que no está», el uruguayo Eduardo Milán argumenta, desde la perspectiva del poeta, la necesidad de la metapoesía. Dice Milán citando a Pessoa-Caeiro: «O vento só fala do vento"», ${ }^{1}$ y se pregunta: «Si el viento sólo habla del viento, ¿por qué un poema debe hablar de otra cosa?». ${ }^{2}$ Pero expone también las reticencias que, desde su punto de vista, despierta la metapoesía:

Se soporta poco el poema que habla del poema, la poesía que habla de la poesía. La poesía todavía debe ser conductora de algo, servir al tema, situarse por debajo de lo que el lenguaje del poema dice. Cuando no es así, a eso que es de veras se le llama metapoesía. O sea: lo que habla de sí mismo está más allá de sí mismo. El metaviento, por ejemplo. El poema fue hecho para hablar de las cosas humanas. «Acostúmbrense a cantar / en cosas de jundamento», dice Martín Fierro. «Cosas de jundamento» son las cosas humanas. El poema como materialidad sigue siendo para el lector medio «fingimiento de cosas bellas / cubiertas y veladas / de muy fermosa cobertura», dice el Marqués de Santillana y repite dos veces la noción de cubrir. ${ }^{3}$

Y aún dirá Milán más adelante:

Poesía es lo que cubre la verdad como un velo de belleza. Y el poema en su materia no aparece en ese trato. Sigue sumergido debajo como lo que posibilita que aquello de arriba pueda ser dicho. Que el poema no aparezca es un pacto de seriedad con el oficio y un homenaje a la humanidad del lector. Es también un odio a la materialidad de la cosa. La cosa seria es la que no muestra su materia. ${ }^{4}$

1 Eduardo Milán: «El poema que no está». In: Visión de cuatro poemas y el poema que no está. Madrid: Libros de la Resistencia, p. 93.

2 Ibid., p. 93.

3 Ibid., p. 93.

4 Ibid., p. 94.

Milena Rodríguez Gutiérrez, Universidad de Granada

๖ Open Access. ( 2021 Milena Rodríguez Gutiérrez, published by De Gruyter. (๕) BY-NC-ND This work is licensed under the Creative Commons Attribution-NonCommercial-NoDerivatives 4.0 International License. https://doi.org/10.1515/9783110736274-005 
Laura Scarano, una de las estudiosas de este «fenómeno autorreflexivo del discurso», ${ }^{5}$ recuerda diversas definiciones del mismo; entre las que cita, puede tomarse la de Federico Peltzer: ${ }^{6}$ "el lenguaje del poema es, a la vez, un lenguaje sobre el lenguaje de la poesía y sobre lo concerniente a esta. ¿Qué hace el poeta en tal caso? Enuncia un programa estético, propone y realiza la creación mediante el poema mismo». ${ }^{7}$

Alex Morillo, siguiendo a Hugo Friedrich en su célebre ensayo, Estructura de la lírica moderna, ofrece también una definición de metapoesía cuando escribe:

[...] lo que encontramos en un texto metapoético es una inteligencia que forja una ficción muy particular desde una concientización que la induce a su desdoblamiento y a su extralimitación en pos de un conocimiento inédito sobre sí misma. Por esta razón, dicha ficción se empeña en desentrañar la relación entre la materialidad creada -la palabra como el punto de fijación pero también de fuga de la significación - y la materialidad que crea - una inteligencia en acto que arma y desarma imágenes y formas para hallar nuevas maneras de experimentar y pensar la poesía. ${ }^{8}$

El metapoema, tal como dice Milán, muestra su materia, habla, sin duda, como el viento, de sí mismo, y es un poema con una sobreabundancia de poesía. Pero, a pesar de la afirmación de Milán, no siempre el poema metapoético deja de hablar de otras cosas, deja de hablar de «cosas humanas». Al menos, eso es lo que pretendo mostrar en este artículo, referido, de manera específica, a cierta poesía, a ciertos poemas metapoéticos escritos por mujeres. Los poemas a los que voy a referirme tienen una característica peculiar: son poemas metapoéticos pero, al mismo tiempo, no lo son; es decir, no son estrictamente o, más bien, no son exclusivamente, poemas sobre la poesía (ninguno se titula, por ejemplo, "Arte poética»); son, diríamos, sobre todo, poemas con la poesía. Porque en ellos más que hablar de la poesía (aunque se hable de ella) se habla con ella, o, quizás mejor, desde ella, y, también, en estos textos, esa materialidad poética a la que alude Milán, no aparece en bruto, por así decirlo. Pero no exactamente porque se pretenda recu-

5 Laura Scarano: «Escribo que escribo: de la metapoesía a las autopoéticas». In: Tropelías. Revista de Teoría de la Literatura y Literatura Comparada 2 (2017), p. 133.

6 Federico Peltzer citado en Laura Scarano: «Escribo», p. 136.

7 Otra definición es la que ofrece Leopoldo Sánchez Torre en su estudio La poesía en el espejo del poema, donde escribe: «[...] diremos que son metapoéticos todos aquellos textos poéticos en los que la reflexión sobre la poesía resulta ser el principio estructurador, esto es, aquellos poemas en que se tematiza la reflexión sobre la poesía» (Leopoldo Sánchez Torre: La poesía en el espejo del poema: La práctica metapoética en al poesía española del siglo XX. Oviedo: Departamento de Filología Española 1993, p. 85).

8 Alex Morillo: La reinvención moderna de la poesía peruana desde la conciencia metapoética (Tesis de máster). Lima: Universidad Nacional Mayor de San Marcos 2017, p. 23. 
brirla de humanidad, o se quiera hablar de «cosas de fundamento», sino porque esa materialidad no se concibe como algo abstracto, sino que se piensa ya mezclada con otros elementos; una materialidad, podríamos decir, impura.

Para estos poemas metapoéticos a los que aludo podría funcionar como modelo el de Alfonsina Storni titulado «Un lápiz», ese antisoneto -así los llamó Alfonsina ${ }^{9}$ - que constituye, en mi opinión, un arte poética implícita. En ese texto, la voz poética, marcada como femenina, se refiere a ese lápiz pequeño y barato, comprado en una esquina por apenas 10 centavos; un lápiz que ella, «distraída», echa en el bolso. ${ }^{10}$ Un lápiz que es metonimia de la escritura y que va agitándose en su bolso y mezclándose en este con todo su contenido: «pañuelos, cartas, / resecas flores, tubos colorantes, / billetes, papeletas y turrones», ${ }^{11}$ mientras la urbana sujeto del poema se mueve, camina por las calles de la ciudad. Un lápiz que, al final del poema, queda definido con una contundente y sugestiva metáfora que da cuenta del poder de la escritura: «[. . .] iba mi bolso con su bomba adentro». ${ }^{12}$

«Un lápiz» pone así de manifiesto cierto rasgo de las metapoéticas, y poéticas, de mujeres: ese mezclar, eso que tal vez podríamos llamar, tomando como referencia este poema de Alfonsina Storni, las «poéticas del bolso». Parafraseando a Alfonsina Storni, podríamos decir de este tipo de poemas metapoéticos: «iba el poema con su poética adentro».

Cabe notar que estas que estoy denominando como «poéticas del bolso» son poéticas que parecen construirse mediante el método propuesto por María Zambrano en Claros del bosque, ese texto fundamental donde la filósofa española comienza la construcción de su «razón poética». En este texto, Zambrano da cuenta de la búsqueda de un método otro, un método opuesto al «método tradicional», ese que es «continuo» frente a una conciencia que, por el contrario, es «discontinua»; ${ }^{13}$ un método tradicional que «se refiere tan sólo al conocimiento objetivo» ${ }^{14}$ y donde el ser queda «desamparado». ${ }^{15}$ Frente a ese «método tradicional», Zambrano propone la utilización de un método «que se hiciese cargo de esta vida, al fin desamparada de la lógica»; ${ }^{16}$ «un método surgido de un «Incipit

9 En 1938 declaraba Alfonsina: «Antisonetos, me permití llamarlos en una colaboración que de otra serie del mismo talante publiqué hace poco en La Nación de Buenos Aires. La denominación puede discutirse; o no tomarse en cuenta.» (Alfonsina Storni: Urbanas y modernas. Crónicas periodísticas de Alfonsina Storni. Valencia: Barlin Libros, p. 177-178).

10 Alfonsina Storni: Antología mayor. Madrid: Hiperión 1997, p. 282.

11 Ibid., p. 282.

12 Ibid., p. 282.

13 María Zambrano: Claros del bosque. Madrid: Cátedra/Fundación María Zambrano 2011, p. 125.

14 Ibid., p. 125.

15 Ibid., p. 125.

16 Ibid., p. 125. 
Vita Nova $>{ }^{17}$ total, que despierte y se haga cargo de todas las zonas de la vida». ${ }^{18}$ Un método, así, discontinuo, como la propia conciencia, como el ser.

Desde esta perspectiva, en la que Storni y Zambrano se cruzan, intento explorar poemas metapoéticos de autoras cubanas. En concreto, voy a detenerme en ciertos poemas de Carilda Oliver Labra (1922-2018), Fina García Marruz (1923), Reina María Rodríguez (1952) y Damaris Calderón (1967).

Los poemas a los que voy a acercarme utilizan modos diferentes de aproximación a la escritura poética, modos diversos de pensar y reflexionar sobre la poesía y el poema; a veces son monólogos; otras, diálogos con la propia poesía; en ocasiones, construcciones aparentemente poco hilvanadas. ${ }^{19}$ Pero, a mi juicio, en todos los casos puede identificarse en ellos esas que estoy llamando las «poéticas del bolso» y, también el empleo, para su construcción, de un método zambraniano «discontinuo», donde caben, además de lo metapoético, «todas»o al menos muchas «zonas de la vida».

\section{Un poema con un siglo y un país adentro: «Una mujer escribe este poema», de Carilda Oliver Labra}

El poema de Carilda Oliver, titulado «Una mujer escribe este poema», forma parte de su libro Desaparece el polvo (1984). Más que un poema-bolso, este es casi un poema-país, un poema-vida, por todo lo que contiene. En este poema, donde imperan las minúsculas y la ausencia de signos de puntuación, asoman la avitaminosis, la cosmonáutica, la bayoneta, el obús, la trombosis coronaria, la bomba, los lentes de contacto, el dinero para el alquiler, la soledad, la preparación combativa, la tristeza, el crepúsculo, el derrame de sinovia, los frijoles que tardan en hervir, el divorcio, la alarma aérea, los niños que duermen en la cuna, el retrato del Che, la pólvora, el rimmel, el uranio, el cobalto, los sueños, la baraja. . .Todo

17 María Zambrano está aludiendo al célebre breviario de Dante, Vita Nuova, donde aparece esta frase.

18 María Zambrano: Claros, p. 125.

19 Merece la pena citar a Leopoldo Sánchez Torre, quien llama la atención sobre «la polisemia del prefijo griego meta», sobre el que escribe: «En origen, pertenecía a la categoría de los adverbios que podían funcionar también como preposiciones, y su sentido primario es en medio de〉 que se desplazó posteriormente en varias direcciones: «entre〉, 〈detrás de`, ‘a continuación〉, 〈por medio de`, 〈junto a〉, «de acuerdo con〉, etc. La lógica ha adoptado un sentido desplazado de meta, que el griego expresaba con peri» (Leopoldo Sánchez Torre: La poesía, p. 20). 
completamente mezclado en el poema. Pero la función de estos elementos, «cosas de fundamento», sin duda, no es la de re-cubrir la verdad del poema, como diría Milán, sino que, por el contrario, su función es la de des-velarla. Porque todos estos elementos están ahí para avisarnos, para mostrarnos, la dificultad, la casi imposibilidad que supone la escritura para ese sujeto poético femenino que, a pesar de todo, se empeña, insiste en escribir. Lo declara el poema desde su comienzo: «Una mujer escribe este poema / donde puede». ${ }^{20} \mathrm{Y}$ continúa:

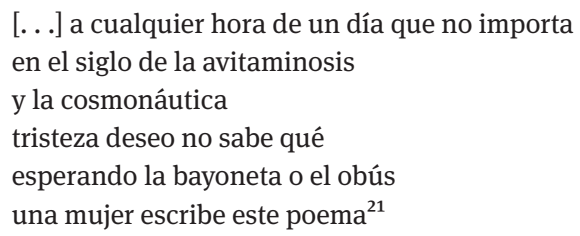

En el texto, la dificultad, la imposibilidad frente a la escritura poética procede de diversas «zonas de la vida», que parecen superponerse para impedir a la voz poética su trabajo y la posibilidad de realizar su vocación de escritora y poeta. Entre estas zonas destacan, sobre todo, dos. En primer lugar, la asociada a la condición femenina de quien escribe, que se muestra tanto en sus obligaciones sociales (la atención a la cocina, simbolizada a través de esos «frijoles» que «se han demorado en hervir» ${ }^{22}$ y en la necesaria crianza de los hijos, esos «niños que duermen en la cuna $»^{23}$ ), como en sus características psicológicas, dadas por esos complejos y a veces contradictorios rasgos que la constituyen («tristeza, deseo, no sabe qué»; $;^{24}$ «fogosa, inalterable, arrepentida»; $;^{25}$ «tonta como balada / «neurótica»;26) y aquí vemos cómo la voz poética hace suyos estos rasgos culturalmente atribuidos a la mujer. En segundo lugar, estaría la zona determinada por el acontecer diario del país, donde rigen, simultáneamente, un ambiente bélico y/o militar (la bayoneta o el obús que se esperan, la bomba que podría sonar, la preparación combativa, la alarma aérea, el «no pasarán ${ }^{27}$ ) y la urgencia vital

20 Carilda Oliver Labra: Error de magia. La Habana: Letras Cubanas 2002, p. 197.

21 Ibid., p. 197.

22 Ibid., p. 198.

23 Ibid., p. 198.

24 Ibid., p. 197.

25 Ibid., p. 197.

26 Ibid., p. 198.

27 Ibid., p. 198. 
(la búsqueda del dinero, de los «quince pesos para el alquiler ${ }^{28}$ ). ${ }^{29}$ Ambas zonas se mezclan en el texto e imponen su marca al sujeto poético femenino, como bien se manifiesta en esos tres espléndidos versos que sintetizan, de manera literal, la carga múltiple que lleva esta mujer poeta que intenta serlo en medio de circunstancias adversas: «cargada de ultimátum / de pólvora / de rimmel». ${ }^{30}$

Otro rasgo, en este caso formal, que también supone la mezcla de elementos diferentes, es la presencia de distintas personas verbales en el poema. Así, aunque en el texto predomina la tercera persona, que aparece, fundamentalmente, en ese verso que se va reiterando, «una mujer escribe este poema», encontramos también la segunda («existes soledad»; ${ }^{31}$ «te juro que mañana presentaré el divorcio»; ${ }^{32}$ ) o la primera del singular («creo en el corazón de Denise Darvall»; ${ }^{33}$ ) o la primera del plural («caemos por turno frente a las estrellas»; «bailamos»; ${ }^{34}$ «hemos ganado porque morimos muchas veces»; $;^{35}$ ) o la segunda del plural («vean si no se han roto los lentes de contacto»; ${ }^{36}$ ) y aún la tercera («no pasarán» ${ }^{37}$ ).

Habría, por último, que detenerse en ese verso «Una mujer escribe este poema», que da título al poema y que se repite hasta ocho veces a lo largo del texto. Es este verso el que encarna, prácticamente en solitario, el nivel metapoético del poema, y resulta revelador en diversos sentidos. Por una parte, da cuenta de la insistencia y persistencia del sujeto poético en la escritura, a pesar de todos los obstáculos, mostrando, tal como afirma Bibiana Collado, que el yo del poema «sólo logra definirse a través de la escritura». ${ }^{38}$ Asimismo, pienso que no debemos dejar de tener en cuenta el tiempo de ese verso, que es, también, el tiempo del poema; ese «escribe», que nos ubica en el presente. Es decir, el verso, y con este el poema, va dando cuenta de la propia escritura mientras esta transcurre, mientras esta se va construyendo. En ese sentido, ese verso sería equivalente a «Una mujer está escribiendo este poema». Se trata de un verso que constituye un enun-

28 Ibid., p. 197.

29 El poema está fechado en 1967 y recoge la realidad cubana de la época, marcada por lo militar y lo bélico; otro elemento epocal, presente en el poema de manera simbólica a través de un retrato, es la presencia de Ernesto Che Guevara, asesinado en Bolivia ese mismo año.

30 Carilda Oliver Labra: Error, p. 198.

31 Ibid., p. 197.

32 Ibid., p. 198.

33 Ibid., p. 198.

34 Ibid., p. 198.

35 Ibid., p. 198.

36 Ibid., p. 197.

37 Ibid., p. 198.

38 Bibiana Collado: «Promesa de transgresión: la feminidad encarnada de Carilda Oliver Labra». In: Iberoamericana 55 (2014), p. 71. 
ciado performativo (Derrida), ese que, como ha estudiado Alex Morillo, ${ }^{39}$ aparece en ciertos poemas metapoéticos; ese enunciado que, a diferencia del enunciado denotativo «supera la función fáctica y se muestra como la expresión que ejecuta una acción a través de las palabras, esto es, signa una circunstancia particular donde el decir revela un hacer que parece concretarse en ese mismo instante». ${ }^{40}$ En este enunciado performativo resulta también esencial el adjetivo demostrativo este, que indica que es «este», y no otro, el poema que escribe «una mujer»; es decir, es al mismo poema que se va haciendo, que se va construyendo a lo largo de la propia escritura, al que se va refiriendo, una y otra vez, el verso. Por otro lado, y aunque pueda parecer contradictorio, este verso termina convirtiendo, sin embargo, esas zonas otras de la vida en elementos involuntarios, pero necesarios, de la metapoesía, porque son esas zonas otras de la vida las que constituyen finalmente, y valga la aparente paradoja, el poema metapoético de la sujeto que escribe. Así, ese «no hay tiempo para la poesía», ${ }^{41}$ que leemos en otro de los versos, a la vez que des-vela la existencia del no-tiempo para escribir, des-vela también lo que la poesía, la escritura, y la poeta que escribe, pueden hacer, a pesar de todo, con ese no-tiempo. Veamos el final del poema:

\author{
[...] una mujer escribe este poema \\ cargada de ultimátum, \\ de pólvora \\ de rimmel \\ verde contemporánea lela \\ entre el uranio \\ $\mathrm{y}$ \\ el cobalto \\ trébol de la esperanza \\ convaleciente de amor \\ tramposa hasta el éxtasis \\ tonta como balada \\ neurótica \\ metiendo sueños en una alcancía \\ ninfa del trauma \\ novia de los cuchillos \\ jugando a no perder la luz en el último tute \\ una mujer escribe este poema. ${ }^{42}$
}

39 Morillo toma como referencia el artículo de Jacques Derrida: «Firma, acontecimiento, contexto» (en Márgenes de la filosofía, trad. de Carmen Fernández Marín. Madrid: Cátedra 2006). 40 Alex Morillo: La reinvención, p. 65.

41 Carilda Oliver Labra: Error, p. 198.

42 Ibid., 198-199. 


\section{La poesía como desciframiento y deseo por venir: Fina García Marruz y el Jardín perdido y recuperado}

El poema de Fina García Marruz, «El jardín», se incluye en su libro Visitaciones (1970). Tal vez sea este, de los elegidos, el poema que propone, en su sentido más literal, un diálogo con la poesía. Aquí, la voz poética se dirige a la poesía a través de una segunda persona, de un tú con el que se habla a lo largo del texto. "Tantas palabras / de otros, ay, haciéndome olvidar / tanto silencio tuyo!», ${ }^{43}$ se le dice a la poesía. Como ocurre en numerosas ocasiones en sus versos, Fina parece partir aquí, y reescribir, a José Martí. ${ }^{44}$ Pienso, por ejemplo, en el último poema, el XLVI, de los Versos sencillos, donde el sujeto poético dialoga con el verso, y donde este es «amigo», «amoroso compañero», «aquel que nunca me deja»; ${ }^{45}$ se trata de ese poema con sugestivo final, donde el héroe y revolucionario se reivindica, sobre todas las cosas, como poeta:

\footnotetext{
¡Verso, nos hablan de un Dios

A donde van los difuntos:

Verso, o nos condenan juntos,

O nos salvamos los dos! ${ }^{46}$
}

Es decir, Martí asume una absoluta radicalidad poética: después de la muerte, el verso y él, él y el verso, irán juntos, del brazo; lo cual equivale a decir que Martí quiere ser pensado, y recordado, como poeta o, en caso contrario, no ser recordado. Se trata de un poema metapoético, pero también, podría decirse, metamartiano: Martí hablando y concibiendo al propio Martí y haciéndolo, ante todo, como poeta.

La radicalidad poética de Fina es diferente a la de Martí; es, podríamos decir, una radicalidad otra. Así, en su diálogo con la poesía, lo que se pretende no es reivindicar la condición de poeta de la hablante lírica, o tal vez sí, pero esa reivindicación vendría, en todo caso, por añadidura. En concreto, su texto pone de manifiesto la elección de esta hablante, que propone la superioridad del mundo

43 Fina García Marruz: El instante raro. (Antología poética). Valencia: Pre-Textos 2010, p. 228. 44 Sobre las cercanías e intertextualidades martianas que aparecen en la obra de Fina García Marruz, puede consultarse el excelente artículo de Luisa Campuzano «José Martí en la poesía de Fina García Marruz». (En : Casa de las Américas 198 (1996), p. 96-97).

45 José Martí: Ismaelillo. Versos libres. Versos sencillos. Madrid: Cátedra 2001, p. 211.

46 Ibid., p. 211. 
poético, del mundo que la poesía construye (mundo por venir, mundo de una realidad otra), frente a la propia realidad, ese mundo ya descifrado, como sin misterio, y visto, sin embargo, o por eso mismo, como una realidad-en falta. Escribe, así, Fina:

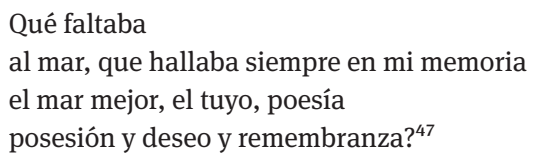

«Deseo y remembranza»; dos sustantivos con los que se define a la poesía: lo que se añora y lo que se sueña; es decir, lo que no es. Y merece la pena recordar ese texto fundamental de Fina, «Hablar de la poesía», su ars poetica en prosa, su reflexión sobre la poesía por antonomasia, que podemos pensar como complemento de «El jardín». Se dice al comienzo de «Hablar de la poesía»: «Lo primero fue descubrir una oquedad: algo faltaba, sencillamente». ${ }^{48} \mathrm{Es}$, así, la falta, la oquedad, la que da lugar, la que origina y propicia la poesía. Poco después aparece el mar también en ese texto, sobre el que escribe: «El mar que tenía delante de los ojos era sólo aquel mar. En el misterioso deseo, en la nostalgia imprecisa, sentía una mayor intensidad de presencia. El mar en un verso de Keats se acercaba más a aquel mar total, bramador como el deseo o la esperanza». ${ }^{49}$ Es decir, como en el «El jardín», el mar de la poesía vuelve a ser un mar «mejor», el mar total.

Más adelante, en el poema, leemos:

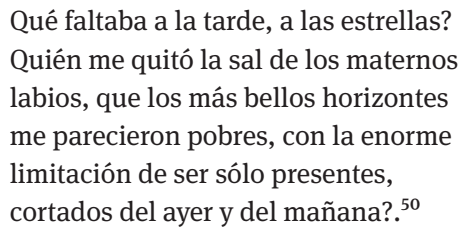

La realidad parece pobre, se vuelve pobre, ante la potencialidad, ante el horizonte que ofrece el universo poético; un modo de percibir que nos recuerda a Heidegger y su afirmación sobre el arte: «[. . .] lo que el arte instaura nunca se

47 Fina García Marruz: El instante, p. 228.

48 Fina García Marruz: «Hablar de la poesía». In: Hablar de la poesía. La Habana: Letras Cubanas 1986, p. 433.

49 Ibid., p. 433.

50 Fina García Marruz: El instante, p. 228. 
compensa ni se suple con lo existente disponible». ${ }^{51}$ Se trata, sin embargo, de un universo frágil. Un horizonte que no es visto como un amigo, como hará Martí, sino como algo lejano, oscuro, indescifrable; la poesía es, así, «casual encuentro», «palabras que no fueron palabras»:

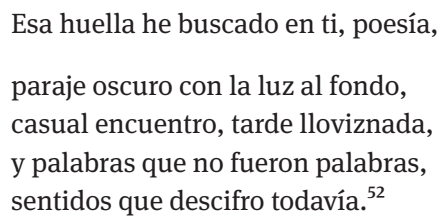

La poesía, así, como aquello que se sigue buscando, aquello que aún no se sabe, la oscuridad con luz: "paraje oscuro con la luz al fondo» $y$, también, «sentidos que descifro todavía». Y al final, aparece, en su plenitud, la mezcla que, en este caso, y como suele ocurrir a menudo en la poesía de Fina, remite al ámbito religioso y católico: la poesía, ese mundo aún por descifrar, ese mundo por-venir, es, en última instancia, el Jardín del Padre, abandonado, que se convierte, gracias a la poesía, en paraíso recuperado; su encuentro supone, por fin, la vuelta a casa, o más bien, a Casa. Aunque habría que recordar también que el jardín, según Foucault, es una heterotopía; uno de cuyos rasgos fundamentales es «yuxtaponer en un solo lugar real múltiples espacios, múltiples emplazamientos que son en sí mismos incompatibles». ${ }^{53}$ Y recuerda Foucault que el jardín, «creación asombrosa ya milenaria, tenía en Oriente significaciones muy profundas y como superpuestas», y que el jardín tradicional de los persas «era un espacio sagrado que debía reunir, en el interior de su rectángulo, cuatro partes que representaban las cuatro partes del mundo». Y termina definiendo el jardín con las siguientes palabras:

El jardín es una alfombra donde el mundo entero realiza su perfección simbólica, y la alfombra, una especie de jardín móvil a través del espacio. El jardín es la parcela más pequeña del mundo y es por otro lado la totalidad del mundo. El jardín es, desde el fondo de la Antigüedad, una especie de heterotopía feliz y universalizante. ${ }^{54}$

51 Martin Heidegger: «El origen de la obra de arte». En Arte y poesía. México: Fondo de Cultura Económica 1998, p. 115.

52 Fina García Marruz: El instante, p. 229.

53 Michel Foucault: «De los espacios otros». Conferencia dictada en el Cercle des études architecturals, 14 de marzo de 1967. In: Architecture, Mouvement, Continuité 5, octubre, 1984. http:// yoochel.org/wp-content/uploads/2011/03/foucalt_de-los-espacios-otros.pdf [Consultado el 8 de octubre 2020].

54 Ibid. 
Si el poema de Carilda era un poema-país, un poema-siglo, el de Fina es un poema-jardín, que equivale a decir, si atendemos a Foucault, un poema-mundo; es decir, un espacio, el espacio casi por excelencia, de la mezcla, de la totalidad. Desde esta visión foucaultiana, este poema-jardín de Fina sería entonces, también, como un bolso, un gran bolso, que de tanto contener, contiene, nada más y nada menos, que el mundo. En esa metáfora o espacio final estaría también contenido, de manera implícita, el método zambraniano discontinuo, pues en ese poema-jardín, o en ese jardín que es la poesía, deben caber, caben, sin duda, «todas» las zonas de la vida. Leamos los últimos versos del poema:

A mi pobreza acudes. Ya me bastas.

Y no deseo más. Miro las ramas

semidesnudas. Imperceptibles tiemblan.

Los troncos en la luz, el breve pájaro

picoteando. Es el inmenso, abandonado

jardín del Padre. Y aquí estamos,

para no irnos, con las vestiduras

rotas del viaje, pero, al fin, en Casa! ${ }^{55}$

\section{Reina María Rodríguez: «La isla de Wight» o el desdoblamiento del yo y la otra que escribe}

«La isla de Wight», de Reina María Rodríguez, es el tercer texto al que propongo aproximarnos. Incluido en La foto del invernadero (1998), se trata de un poemamonólogo, aparentemente; escrito en minúsculas, como el de Carilda, aunque con algunos signos de puntuación, puntos y seguido; un rasgo que aparece con frecuencia en la escritura de la autora. ${ }^{56}$ Tanto el poema de Reina María como el de Damaris Calderón, revelan, a través de distintos elementos, su estatuto radicalmente contemporáneo. En «La isla de Wight», las reflexiones sobre el ser -un ser que se va mostrando como discontinuo, como desamparado, a lo largo del poema-, enunciadas por un sujeto marcado como femenino, se van alternando

55 Fina García Marruz: El instante, p. 230.

56 En La foto del invernadero todos los poemas utilizan este recurso: una minúscula que abre el poema, o la prosa poética - que también aparece en este libro-, una frase que se cierra con un punto y seguido, y otra que sigue a continuación y que empieza nuevamente con una minúscula. Así, por ejemplo, en el comienzo del poema «-al menos, así lo veía a contra luz-», donde leemos: «he prendido sobre la foto una tachuela roja. / -sobre la foto famosa y legendaria» (Reina María Rodríguez: La foto del invernadero. La Habana: Letras Cubanas, p. 17). 
con las reflexiones en torno al poema y a la poesía. La instancia existencial y la instancia poética se hallan así dentro del poema:

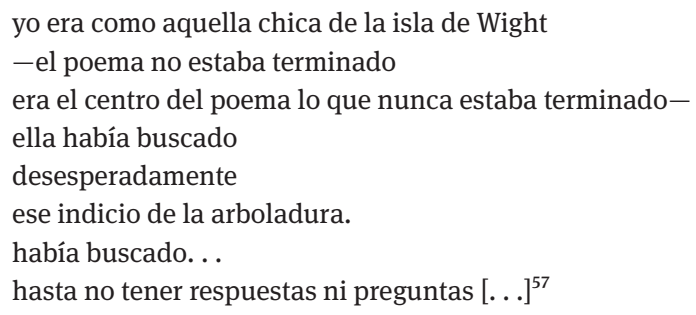

Como ocurre en el de Carilda, el poema contiene también varias personas del verbo, en concreto, la primera y la tercera del singular; el yo y el ella, pero, en este caso, se trata de un yo que se va desdoblando. Es decir, aparece aquí ese estatuto «doppelgänger» propio de la metapoética, que al decir de Romano Sued, «parodia, replica, discute o refirma el discurso 〈principal de los textos». ${ }^{58}$

La aparición de la tercera persona, ese ella, tiene así un efecto de extrañamiento en el poema: el yo se distancia de sí mismo y se mira, se autoexamina, se autoanaliza, de manera rimbaudiana, como si fuera otro, u otra. Je est un autre, había dicho Rimbaud; Yo es otra, parece decirnos aquí Reina María. (¿Significarán lo mismo, por cierto, el otro y la otra?). Y esa otra es precisamente la que sabe, la que mira y analiza al desamparado yo al que convierte en ella: «ella había buscado / desesperadamente / ese indicio de la arboladura. / había buscado hasta no tener respuestas ni preguntas»..$^{59}$

Al comienzo del poema, tal como se aprecia en el fragmento anterior, las reflexiones metapoéticas van surgiendo a modo de acotaciones, como en un registro paralelo al transcurrir del que parece ser el asunto principal, los asuntos del ser. La función de esas acotaciones-reflexiones es, pues, la de intentar ordenar

57 Reina María Rodríguez: La foto, p. 12.

58 Susana Romano Sued: «Metapoéticas». En Susana Romano Sued, Agustín Berti y Tomás Vera: Exposiciones. Metapoéticas de literatura argentina: Martínez Estrada-Lamborghini-SaerTizón. Córdoba: El Emporio; Epoké 2011, p. 15.

59 Recordemos que, como señala Ángel Rama destacando los descubrimientos de Rimbaud y de Martí en torno a la otredad subjetiva, «habría dos fuentes separadas del actuar y del conocer, un 〈yo〉 y un 〈otro〉. Este último no solo sabe más sino que registra la existencia de las 〈leyes〉 rectoras, muy por encima de lo que puede percibir la subjetividad personal, vista como reducida y escasamente poderosa» (Ángel Rama: «José Martí en el eje de la modernización poética: Whitman, Lautréamont, Rimbaud». In: Martí, modernidad y latinoamericanismo. Caracas: Fundación Biblioteca Ayacucho 2015, p. 218-219). 
la discontinuidad del ser. Ante la percepción de la discontinuidad del ser, de su fractura (el yo «que se agrieta») el poema se ofrece así como una posibilidad de orden, como puede verse en este otro fragmento:

\author{
[...] se que esa mentira que ha buscado \\ obtiene algún sentido al derretirse \\ en sus ojos oscuros. ha buscado el abrupto sentido del sentir \\ que la rodea. \\ (un poema es lo justo, lo exacto, lo irrepetible \\ dentro del caos que uno intenta ordenar y ser) $[\ldots]^{60}$
}

Hacia la mitad del poema, sin embargo, esos dos registros empiezan a confluir, gracias a la otra, que se ha ido situando, desde el comienzo, como hemos dicho, lejos, distanciada del yo, pero, simultáneamente, cada vez más cerca del poema y de la escritura; y es que es esa otra, más que el yo, quien parece saber de la escritura; es, incluso, esa otra quien parece estar escribiendo el poema; es decir, como diría Romano Sued, esa otra estaría «refirmando» el poema. Y cabe traer aquí las palabras de Ángel Rama sobre Rimbaud y Whitman y sus hallazgos sobre el papel del otro en la escritura, en la poesía:

\begin{abstract}
En el momento correspondiente a los modernizadores, se percibe la génesis espontánea de la poesía en el psiquismo bajo la mirada atenta de un yo; este, merced a un subrepticio desdoblamiento, deviene un testigo, en el mejor de los casos un colaborador experto, de una operación creadora que realiza dentro del psiquismo un extraño, un autre cuya denominación es difícil y escurridiza, porque ya puede ser un paralelo del «yo» consciente y entonces es posible de ser encajado en una dicotomía tradicional, mediante reacomodación de sus términos, designándolo con el nombre de «alma», ya puede percibirse que es el «yo» terrenal, no metafísico, que se ha enajenado en otro. ${ }^{61}$
\end{abstract}

Y sigue diciendo Rama: «[. . .] el fenómeno es autocontemplado por el escritor, con inquietud y perplejidad, sin lograr despejar su significación pero comprobando su existencia». ${ }^{62}$

«La isla de Wight»es, así, una constatación de ese fenómeno de la escritura extrañada, enajenada, realizada por un otro-otra; una otra que, como decíamos, es la que está verdaderamente cerca del poema, es quien escribe, quien «refirma» el poema. Sin embargo, hay en este texto una inversión en los papeles, porque no es el yo quien contempla, extrañado, a esa otra; es la otra, insistimos, la que habla, la que contempla al yo como si este fuera un extraño:

60 Reina María Rodríguez: La foto, p. 12.

61 Ángel Rama: «José Martí», p. 212.

62 Ibid., p. 212. 


\author{
[...] despojada del poema y de mí \\ va buscando con su pasión de perseguir \\ la dualidad. ha perdido, ha buscado. \\ ha contrapuesto animales antagónicos que han venido a morir \\ bajo mi aparente neutralidad de especie, \\ un gato, un pez, un pájaro. .. sólo provocaciones. ${ }^{63}$
}

Antes de llegar al final, de repente, de manera inesperada, entre el yo y el ella surge la segunda persona; un tú fugaz; la otra parece de pronto acercarse, hablarle al yo: «-te digo que los mires - / para hallar otra cosa entre esa línea demoledora de las formas / que chocan al sentir su resonancia». ${ }^{64}$ La otra le habla al yo y alude también a la escritura, a la necesidad de estar en ella. Es a partir de este momento y ya en los últimos versos en que empieza a producirse la mezcla de los dos registros, el ser y la escritura y, llamativamente, también el acercamiento, la fusión entre el yo y la otra. El ser y el poema se mezclan, se juntan, confluyen, al mismo tiempo en que confluyen el yo y su otra. Aunque comienzan con ese verso-estribillo que se reitera a lo largo del texto, «yo era como aquella chica de la isla de Wight», ${ }^{65}$ esos últimos versos parecen así ser enunciados ya no por esa otra sino por el yo, que está dispuesta al encuentro, que percibe que puede realizarse a través del poema, de la escritura, y aún de su falta, de sus tachaduras. $\mathrm{El}$ encuentro con el ser, el encuentro con la otredad que somos, parece decirnos Reina María, puede producirse, se produce, a través de la escritura del poema, y no sólo de lo que esta consigue en un sentido positivo, sino, quizás, todavía más, de aquello que no se consigue; es decir, a través de ese resto, o residuo, que son sus tachaduras. La materialidad del poema, sus tachaduras, sus borrones, suponen así el acceso a esa «otra zona» zambraniana de la vida. Y, asimismo, el peso que aquí tiene la materialidad, el residuo, hace que en este poema se verifique la idea de Guillermo Sucre sobre la poesía contemporánea, que le hace distinguir el «obrar» de la «Obra» y escribir: «Toda obra es anti-obra en la medida [...] en que no es, no puede ser, la Obra. El absoluto de la poesía reside en una imposibilidad que, sin embargo, se vuelve una continua posibilidad: el poema nunca está hecho sino perpetuamente haciéndose (¿y, por ello mismo, deshaciéndose?)». ${ }^{66}$ «La isla de Wight» es, también, eso, un poema que exhibe «el obrar»

63 Reina María Rodríguez: La foto, p. 13.

64 Ibid., p. 13.

65 Ibid., p. 13.

66 Guillermo Sucre: La máscara, la transparencia. México: Fondo de Cultura Económica 2001, p. 229. 
y su distancia con la Obra; un texto que está, continuamente, haciéndose, o deshaciéndose:

\author{
yo era como aquella chica de la isla de Wight \\ había buscado en lo advenedizo \\ la fuga y la permanencia de lo fijo y me hallo \\ dispuesta a compartir con ella a través de las tachaduras \\ si el poema había existido alguna vez materialmente \\ si había sido escrito ese papel \\ para conservar el lugar de una espera. ${ }^{67}$
}

\title{
4 Damarys Calderón: «Mis 5 malditos minutos». La vocación poética y el uppercut en el estómago
}

En este último apartado vamos a detenernos en la propuesta de Damaris Calderón, la de su poema «Mis 5 malditos minutos», incluido en su libro Las pulsaciones de la derrota (2013). Este poema indaga en el sentido de la escritura, indaga en torno a por qué se escribe y en torno a lo que se está dispuesto a hacer por esa vocación de poeta, de artista. Como suele ocurrir en la poesía de Damaris, la ironía y la violencia son protagonistas en estos versos.

Desde su título, el poema establece una continua relación de intertextualidad con Charles Bukowski; el título y el exergo con el que el poema comienza están tomados del poema de Bukowski «La muerte se está fumando mis cigarros». El verso de Bukowski, «Mis 5 malditos minutos», va a convertirse en leitmotiv y en contrapunto irónico en el texto de Calderón. El poema de Bukowski es también, a su modo, al modo del poeta maldito que fue, un poema metapoético, como el de Damaris. El escritor norteamericano reivindica la poesía y el sentido de la escritura: «5 malditos minutos», por los que se está dispuesto, por los que se pasa, incluso, hambre; «5 malditos minutos» que valen mucho más que el dinero o la fama; «[. . .] 5 malditos minutos / 5 horas, / 5 días» ${ }^{68}$ para poder «[...] escribir la palabra / justa» ${ }^{69}$ y burlar, así, a la muerte. La fugacidad de la vida contrarrestada por el sentido que se le da, determinado por la escritura, por el

67 Reina María Rodríguez: La foto, p. 13.

68 Charles Bukowski: La muerte se está fumando mis cigarros (últimos poemas). Santiago de Chile: Bajo el Volcán 1996, p. 61.

69 Ibid., p. 61. 
arte, por el propio hecho de escribir. Pero si en el poema de Bukowski el sujeto poético elige el arte, «su» arte, y junto a este el hambre, en una actitud de rebeldía, despreciando la «fábrica de producción», la «tienda de departamentos», ${ }^{70}$ previstos como destino en la sociedad utilitarista, en el de Calderón, por el contrario, el sujeto poético, marcado como femenino («yo misma»), sugiere haber evitado el hambre mediante la beca Guggenheim; es decir, entrando a formar parte, ella misma, del entramado utilitarista, mercantil, que gira en torno al arte. En contraste con el de Bukowski, el sujeto poético femenino de Calderón no elige, decíamos, pasar hambre por su arte: se coloca allí, doblándose, se expone en esa nueva «tienda de departamentos» del arte, a pesar, incluso, de despreciar, según dice, «a Simon y a Peggy Guggenheim», ${ }^{71}$ convirtiéndose en parte de ese «museo de arte de mascotas». ${ }^{72}$ Por cierto que la perspectiva, la mirada de este sujeto poético de Calderón sobre el museo Guggenheim recuerda a la de Baudrillard ante el Beaubourg - antecedente del Pompidou-: «hipermercado» de la cultura que muestra «la hiperrealidad de la mercancía», ${ }^{73}$ donde el objeto artístico circula de manera «acelerada»; ${ }^{74}$ un museo que es así "proceso de simulación ininterrumpido», ${ }^{75}$ con la función de "producir masa»; ${ }^{76}$ un museo de «cultura fetichizada». ${ }^{77}$ Sin embargo, en medio de esa especie de simulación, de brillo falso, la palabra poética, «su arte», se impone, se abre paso, tal como transmite, con gran intensidad, ese verso de una única palabra solitaria, ese verso con un único verbo conjugado en primera persona: «escribí». ${ }^{78}$ Verso, así, de una «intransitividad radical», en el sentido en que dijera Foucault. ${ }^{79}$ Un verbo que no necesita com-

70 Ibid., p. 61.

71 Damaris Calderón: Las pulsaciones de la derrota. Santiago de Chile: LOM 2013, p. 68.

72 Ibid., p. 68.

73 Jean Baudrillard: Cultura y simulacro. Barcelona: Kairós 1978, p. 89.

74 Ibid., p. 90.

75 Ibid., p. 89.

76 Ibid., p. 89.

77 Ibid., p. 92. La presencia metaliteraria de la beca Guggenheim en el poema y el supuesto efecto perturbador de la obtención de dicha beca en la propia escritura nos hace recordar el poema de Tamara Kamenszain titulado «La novela de la poesía», cuya tercera parte se inicia con los versos: «Cuando ganó la beca Guggenheim / para escribir La novela luminosa / Mario Levrero empezó escribiendo 〈El diario de la beca〉 / para no escribir La novela luminosa.» (Tamara Kamenszain: La novela de la poesía. Poesía reunida, ed. Violeta Kesselman, pról. Enrique Foffani. Buenos Aires: Adriana Hidalgo 2012, p. 391). Es probable que el poema de Calderón establezca también una relación de intertextualidad con este de Kamenszain, incluido en su Poesía reunida, publicada en 2012, es decir, un año antes que Las pulsaciones de la derrota.

78 Damaris Calderón: Las pulsaciones, p. 68.

79 Al hablar de la literatura del siglo XX, fundamentalmente de la segunda mitad, dice Foucault: «[ . . ] la literatura se distingue cada vez más del discurso de ideas y se encierra en una in- 
plemento directo para expresar su sentido sino que, al contrario, precisamente porque no hay un complemento directo acompañándolo expresa su significado con mayor fuerza; fuerza que se intensifica con esos blancos que siguen al verbo en la misma línea y al comienzo del verso siguiente y con el complemento circunstancial de lugar implícito: escribí en medio de ese «museo de mascotas». Como el «escribe» de Carilda, el «escribí» de Damaris es esencial en el poema. Si en el de Carilda, el verbo escribir conjugado en presente y en tercera persona daba su pleno sentido al poema e incluso lo iba haciendo, en el de Damaris, el mismo verbo, conjugado en pasado y en primera persona, constituye también su núcleo que, en este caso, es revelación de la vocación de poeta de la sujeto hablante; no, así, un escribir «como (se) puede» en medio de los obstáculos, que diría Carilda, sino un «pude escribir» con autenticidad, pude escribir a pesar de todo, incluso allí, en medio del brillo del simulacro del arte. En este momento, la escritura, la palabra, se convierten, finalmente, en acto de rebeldía, que termina igualando a esta sujeto poético -aunque se produzca en un movimiento posterior, en un movimiento en cierto modo inverso-, con el de Bukowski; en una rebeldía otra que consiste no en renunciar, en principio, a la «tienda de departamentos», sino en entrar en ella, y escribir en medio de ella, en medio de ese «museo de arte de mascotas», mientras esta escritura, a la vez, delata la máscara y denuncia, simultáneamente, lo que esta «tienda», lo que este «museo» es.

La escritura, el acto de escribir, devuelve a la sujeto hablante su sentido, en su significado sobreabundante, polisémico, que abarca la materia y el alimento («el hueso / arrancado a la noche»), el «deseo» y también el propio cuerpo («el cuerpo humeante», «un uppercut al estómago»). ${ }^{80}$ Habría acaso que detenerse en uno de estos sentidos, el del uppercut, que es ese golpe del boxeo que se da en la pelea cuerpo a cuerpo, de abajo a arriba ${ }^{81}$ Un verso que continúa afianzando el diálogo con Bukowski de manera metonímica, en su remisión al estómago, el órgano por excelencia del hambre; en el poema de Damaris, la escritura termina repercutiendo así en el mismo órgano corporal, aunque no sea a consecuencia del hambre que el hecho de dedicarse a esta puede suponer, sino del brusco, impactante golpe en el estómago que ella misma constituye cuando es auténtica. Ese «uppercut en el estómago» es un signo de violencia, de esa violencia que

transitividad radical» (Michel Foucault: Las palabras y las cosas. Una arqueología de las ciencias humanas. Buenos Aires: Siglo XXI 1968, p. 294).

80 Damaris Calderón: Las pulsaciones, p. 68.

81 Llamativamente, Yoandy Cabrera se ha referido a la escritura de Damaris con la siguiente frase: «Como en un gimnasio, las palabras desnudas entrenan sus cuerpos sudorosos y vitales». (Yoandy Cabrera: «Damaris Calderón: el doloroso arte de rumiar palabras». In: Damaris Calderón: El infierno otra vez. La Habana: Unión 2010, p. 20). 
suele aparecer en los poemas de Damaris Calderón; una violencia que, en este caso, trasciende la del poema de Bukowski y revela además la dimensión residual de eso otro, ese resto que queda en la escritura después de la palabra y que muy bien expresa Roland Barthes: «La escritura misma [. . . ] es violenta. Es justamente lo que hay de violencia en la escritura lo que la separa de la palabra, lo que revela en ella la fuerza de inscripción, la añadidura de un trazo irreversible». ${ }^{82}$

Al final del poema hace su aparición la muerte. Esa «nena», que se «fumaba» los cigarros del sujeto poético en el poema del autor de Factotum y se paseaba por sus versos a lo largo del texto, tiene en el poema de Calderón una presencia más discreta y abstracta, sin personificación como mujer («Y la muerte me alcanzará de todos modos» ${ }^{83}$ ), aunque no menos decisiva. De hecho, podemos decir que la muerte en el poema de Damaris revela su condición de «catástrofe», condición a la que se ha referido Francine Massiello; porque es precisamente esa catástrofe mayor que es la muerte, o la conciencia de su existencia, la que otorga su mayor sentido a la escritura y la que hace que el propio cuerpo sea una superficie privilegiada para sentir, o escribir, sus efectos. Como escribe Masiello: «[. . .] la literatura trabaja la coyuntura entre la vida y la muerte: en los bordes de la crisis, el cuerpo se convierte en la superficie que muestra las marcas de este 〈evento»». ${ }^{84}$ Junto a la muerte, están también, en el poema de Calderón, esos otros «eventos» catastróficos de distinto orden: el miedo, el frío, la soledad. Ellos, también, justifican la escritura. El poema termina reivindicando así la escritura y su sentido, un sentido profundo, que vuelve a colocar al sujeto poético del poema de Calderón al lado del de Bukowski, porque se escribe, según se dice al final del poema: «No para calentarse al fuego mendigo»; es decir, no para poder entrar en «tiendas de departamento», o en los «museos de arte de mascota»; no para abrigarse y estar a salvo y dejar de pasar hambre, sino, al contrario, «para arder en el pozo solo, / que asciende de lo hondo a lo hondo, sin raíz». Una defensa de la poesía y del ser-poeta por encima de todo, durante esa frágil, corta, maldita representación que es la vida. Y aquí, una vez más, la escritura remite al cuerpo, con ese verbo que lo representa, ese arder: la escritura, la poesía se convierten en signo de un fuego otro, diferente y opuesto al fuego «mendigo»; un fuego que no protege de la soledad, del miedo; un fuego que, sin embargo, se inscribe, se escribe, en el cuerpo y lo hace, como todo fuego verdadero, arder.

82 Roland Barthes: «La escritura del suceso». In: El susurro del lenguaje. Más allá de la palabra y de la escritura. Barcelona: Paidós 1994, p. 193-194.

83 Damaris Calderón: Las pulsaciones, p. 68.

84 Francine Masiello: «Cuerpo y catástrofe». In: El cuerpo de la voz (poesía, ética y cultura). Buenos Aires: Beatriz Viterbo 2013, p. 264. 
Junto al poema de Carilda Oliver, es quizás este de Damaris el que mejor nos acerca la metáfora del bolso de Alfonsina; un bolso que es, también aquí, la propia vida; ese sitio donde entran, donde caen y se mezclan, el arte, el hambre, Bukowsky, Simon y Peggy Guggenhaim y su museo con sus colecciones de «mascotas», la propia artista y esa beca que tuvo allí, a la que se alude sin nombrarla explícitamente; la muerte que acecha, la soledad, el miedo, el cuerpo; y allí, en medio, el lápiz, es decir, la poética, ese «escribí», la «bomba adentro», la poesía, la escritura. Un bolso construido con el método zambraniano, donde el sujeto poético queda desamparado, desprotegido ante ese fuego otro, antilógico, que es la escritura de la poesía, que no abriga ni protege, pero que, sin embargo, arde. Veamos, para terminar, el poema de Damaris Calderón:

Por mi arte pasé hambre. Pasé hambre mis cinco malditos minutos

Bukowski

Doblándome

(literalmente)

como el insecto que carga una hoja

el doble de su peso

despreciando a Simon y a Peggy Guggenheim

y a su colección de perros

y a su colección de cuadros

y a su museo de arte de mascotas

de la que yo misma entré a formar parte,

escribí.

Y la palabra fue el hueso

arrancado a la noche

el cuerpo humeante el deseo

un uppercut al estómago.

Y la muerte me alcanzará de todos modos.

De verdad hace miedo y frío y soledad

$\mathrm{y}$ tal vez por todo eso uno escribe.

No para calentarse al fuego mendigo

sino para arder en el pozo solo,

que asciende de lo hondo a lo hondo, sin raíz. ${ }^{85}$

85 Damaris Calderón: Las pulsaciones, p. 68-69. 


\section{Bibliografía}

Barthes, Roland: «La escritura del suceso». In: El susurro del lenguaje: Más allá de la palabra y de la escritura, trad. C. Fernández Medrano, p. 189-195. Barcelona: Paidós 1994.

Baudrillard, Jean: Cultura y simulacro, trad. Pedro Rovira. Barcelona: Kairós 1978.

Bukowski, Charles: La muerte se está fumando mis cigarros (últimos poemas), trad. y sel. Yanko González y Pedro A. Araya. Santiago de Chile: Bajo el Volcán 1996.

Cabrera, Yoandy: «Damaris Calderón: el doloroso acto de rumiar palabras». In: Damaris Calderón: El infierno otra vez, p. 5-21. La Habana: Unión 2010.

Calderón, Damaris: Las pulsaciones de la derrota. Santiago de Chile: LOM 2013.

Campuzano, Luisa: «José Martí en la poesía de Fina García Marruz». In: Casa de las Américas 198 (1996), p. 96-97.

Collado, Bibiana: «Promesa de transgresión: la feminidad encarnada de Carilda Oliver Labra». In: Iberoamericana 55 (2014), p. 49-74.

Foucault, Michel: Las palabras y las cosas. Una arqueología de las ciencias humanas, trad. Elsa Cecilia Frost. Buenos Aires: Siglo XXI 1968.

-: «De los espacios otros», trad. Pablo Blitstein y Tadeo Lima [Des espaces autres]. Conferencia dictada en el Cercle des études architecturals, 14 de marzo de 1967. In: Architecture, Mouvement, Continuité 5, octubre, 1984. http://yoochel.org/wp-content/ uploads/2011/03/foucalt_de-los-espacios-otros.pdf [Consultado el 8 de octubre 2020].

García Marruz, Fina: «Hablar de la poesía». In: Hablar de la poesía, p. 433-441. La Habana: Letras Cubanas 1986.

-: El instante raro. (Antología poética), ed. e intr. Milena Rodríguez Gutiérrez. Valencia: Pre-Textos 2010.

Heidegger, Martin: «El origen de la obra de arte». In: Arte y poesía, trad. y pról. Samuel Ramos, p. 35-123. México: Fondo de Cultura Económica 1988.

Kamenszain, Tamara: La novela de la poesía. Poesía reunida, ed. Violeta Kesselman, pról. Enrique Foffani. Buenos Aires: Adriana Hidalgo 2012.

Martí, José: Ismaelillo. Versos libres. Versos sencillos, ed. Ivan A. Schulman. Madrid: Cátedra 2001.

Massiello, Francine: «Cuerpo y catástrofe». In: El cuerpo de la voz (poesía, ética y cultura), p. 255-272. Buenos Aires: Beatriz Viterbo 2013.

Milán, Eduardo: «El poema que no está». In: Visión de cuatro poemas y el poema que no está, p. 87-106. Madrid: Libros de la Resistencia 2016.

Morillo, Alex: La reinvención moderna de la poesía peruana desde la conciencia metapoética (Tesis de Máster). Lima: Universidad Nacional Mayor de San Marcos 2017.

Oliver Labra, Carilda: Error de magia, sel. y notas Mayra Hernández Menéndez; pról. Virgilio López Lemus. La Habana: Letras Cubanas 2002.

Rama, Ángel: «José Martí en el eje de la modernización poética: Whitman, Lautréamont, Rimbaud». In: Martí, modernidad y latinoamericanismo, sel. Julio Ramos y María Fernanda Pampín; pres. María Fernanda Pampín, p. 192-232. Caracas: Fundación Biblioteca Ayacucho 2015.

Rodríguez, Reina María: La foto del invernadero. La Habana: Casa de las Américas 1998. Romano Sued, Susana: «Metapoéticas». In: Susana Romano Sued, Agustín Berti y Tomás Vera: Exposiciones. Metapoéticas de literatura argentina: Martínez Estrada-LamborghiniSaer-Tizón, p. 11-18. Córdoba [Argentina]: El Emporio; Epoké 2011. 
Sánchez Torre, Leopoldo: La poesía en el espejo del poema. La práctica metapoética en la poesía española del siglo XX. Oviedo: Departamento de Filología Española 1993.

Scarano, Laura: «Escribo que escribo: de la metapoesía a las autopoéticas». In: Tropelías. Revista de Teoría de la Literatura y Literatura Comparada 2 (2017), p. 133-152.

Storni, Alfonsina: Antología mayor, sel. y ed. Jesús Munárriz; introd. Jorge Rodríguez Padrón. Madrid: Hiperión 1997.

-: Urbanas y modernas. Crónicas periodísticas de Alfonsina Storni, coord. Mariela Méndez, Graciela Queirolo y Alicia Salomone; pról. Berta García Faet. Valencia: Barlin Libros 2019. Sucre, Guillermo: La máscara, la transparencia. México: Fondo de Cultura Económica 2001 [1975].

Zambrano, María: Claros del bosque, ed. Mercedes Gómez Blesa. Madrid: Cátedra/Fundación María Zambrano 2011. 